\section{LECCIONES DE ANTROPOLOGIA}

(Acaban de aparecer impresas las Lecciones de Antropología dictadas por el doctor Julián Restrepo Hernández en el Colegio del Rosario. Es una obra que honra a su autor $\mathrm{y}$ al instituto de donde procede; es fruto de una labor de veinticinco años, es libro católico y tomista en que se han aprovechado los descubrimientos científicos modernos. Mientras pluma más imparcial que la nuéstra se encarga de juzgar este nuevo trabajo, insertamos el prólogo del autor, a quien enviamos un aplauso sincero y una voz de aliento para no desmayar en la tarea).

\section{PREFACIO}

Cuando en 1907 imprimi las Lecciones de Lógica, tenia en preparación el Derecho internacional privado que di a la estampa por 1914, y las Lecciones de Antropologia que, terminadas hacia 1915, entrego hoy al público, dedicadas a Monseñor Rafael Maria Carrasquilla.

Siendo él Ministro de Instrucción Pública del señor don Miguel Antonio Caro, me nombró profesor de Derecho administrativo en la Facultad de Bogotá; de ahí surgió la Codificación cundinamarquesa editada oficialmente, gracias al general Juan N. Valderrama y al doctor José Maria Pinto, en 1900, y que contiene toda nuestra legislación y reglamentos administrativos que a la sazón imperaban en el orden nacional y en el cundinamarqués. Más antes habia Monseñor entrado a regir el Colegio Mayor de Nuestra Señora del Rosario-instituto secular, cuna de la República-por designación del Presidente, doctor Carlos Holguin, y al año siguiente, 1892, me habia entregado la cátedra de Lógica y Antropología (que habia yo desempeñado alli en 1890). En 1912 me confió la de Derecho internacional privado, y así hube de terminar e imprimir el fruto de mis labores en esa ciencia jurídica. También me creó temporalmente catedrático del antiguo Derecho real español. No me preocupé por escribir el opúsculo correspondiente, porque he creido para mi insuperable la preciosa obra de don Juan Sala y porque estoy cierto de que tal como él y sus contemporáneos entendieron el Derecho real. de España es como éste ha sido fuente y origen de nuestra legislación civil.

No sólo estos motivos, enteramente personales, exigen que ofrende yo este opúsculo a Monseñor Carrasquilla. El mucho más importante de ser él cabeza del movimiento neotomista hace que yo honre asi mi modesto trabajo. Aqui él ha impreso a ese movimiento, salvador de la ciencia, carácter netamente nacional; él no es, como se considera a Zeferino González en España, simple comentador de Santo Tomás.

Si allá quisieran leer las publicaciones del Colegio del Rosario, el catedrático de filosofía señor Eloy Luis André, al hablar del movimiento filosófico de Suramérica, en 1911, no habria preterido a Colombia y no habria dicho el enorme error de que los suramericanos apenas son discipulos de los franceses.

Hace más de treinta años que eso no es verdad en Colombia. En los que precedieron a 1886, se habia estrechado el estudio filosófico oficial a la criteriolugia o ciencia del conocimiento y a la psicología humana. Cierto que entonces se puso en manos de la juventud un abigarrado conjunto de fragmentos contradictorios bajo el impropio nombre de Curso de filosofía experimental donde alternan ingleses y franceses. Pero en criteriologia prevaleció Stuart-Mill con su sistema inductivo, anticientífico cual lo califica y demuestra el eminente lógico inglés Welton, y con su enemistad por la deducción y los demás criterios que, por consecuencia, quedaron amputados de la enseñanza pero no de la naturaleza. En psicología se trataba de seguir a Spencer, a quien pocos entendieron por deficiencia en cono- 
cimientos de ciencias naturales, que son el material spenceriano, y por carencia de ideas trascendentales, espiritu semikantiano bajo el cual se amparan las generalizaciones del ingeniero-filósofo. Tales enseñanzas, mútilas e incoherentes, nada tenían de francesas.

A partir de 1886 se inició la enseñanza oficial de filosofía católica, siguiendo el Compendio de Sanseverino o Vallet y a Prisco, y por medio de ellos a Santo Tomás. Esas obras no son de filosofía francesa. Compuestas para otros países, no respondieron a nuestras necesidades científicas y sociales. Hemos estado en ciencias, más atrás del principio, si bien hemos tenido sabios como Vargas Reyes, Juan de Dios Carrasquilla, Zerda, Montoya y Flórez, etc., que por ser lumbreras esporádicas no han podido fundar escuela. Sin conocimientos sólidos en filosofía no hay terreno propicio en la mente humana para el nacimiento y prosperidad de las ciencias. Preciso nos era, en criteriología, afirmar la inducción sobre cimiento científico y restaurar el estudio de todos los criterios de que está dotada la naturaleza humana; en psicología necesitábase, pésele a Compte, poner a contribución ciertas ciencias médicas y experimentales para fijar científicamente la naturaleza de nuestras potencias, la de nuestra alma y la de nuestra especie, en el individuo y en el sexo. La metafísica habia que hacerla toda. Apremiante era también infiltrar en la juventud espiritu de razonable tolerancia como triaca al de combativo sectarismo que corroía las entrañas de la Patria. Monseñor Carrasquilla coronó con éxito felicisimo la construcción de la metafísica; me ha tocado la tarea de la lógica y la psicología; pero es él quien ha encauzado por el amplio lecho de las necesidades patrias la copiosa y fluente vena de la filosofía tomista.

La nacionalización de las ciencias, las artes y las industrias es la creación del alma nacional, que hace de la Patria una persana y la emancipa de las demás. Un pais que piensa y vive del extranjero es mísera colonia. Sus ideas, sus obras y su comercio propio lo hacen factor en la obra de la civilización y lo cambian de satélite en planeta en el sistema internacional del progreso. "No sometamos el espíritu a otro pueblo." (Fichte). Nada tan patriótico como nacionalizar la ciencia. Por eso en mi Derecho internacional privado abominé del injustificable afrancesamiento de nuestra teórica juridica. En filosofía se palpa sello colombiano: la absoluta falta de justo estimulo tiene la planta atrofiada. Nuestro profesorado se paga con "raciones de hambre," el lauro de sus obras es la conspiración del silencio, cuando no murmuraciones ininteligentes, y sus personas son coronadas con las espinas de la contumelia y azotadas con las más repugnantes intrigas. Aun se amenaza, como para extirpar todo aliento nacional, con traernos liberalmente honrados y remunerados profesores extranjeros, y nada menos que de sociología, como si se pudiera fijar esa ciencia, eminentemente experimental, sin conocer la historia, usos, hábitos y costumbres de la sociedad que estudie. Antaño trajeron maestros alemanes para enseñar a leer el castellano.

Absurdo sería que al nacionalizar una ciencia se la hiciera de nuevo. Al adoptar patria un individuo no cambia de naturaleza. La carta de ciudadanía de una ciencia está en tomarla en su mejor fuente y desarrollo y adaptarla haciéndola progresar, a las necesidades y circunstancias del país. $Y$ ¿qué mejor fuente y más amplio y mesurado desarrollo, en filosofía, que las enseñanzas de Santo Tomás de Aquino, el príncipe de los filósofos católicos, para quien el adversario no es el enemigo a que deba desvalorarse con injurias, sino vencerse con razonamientos, quien ama la verdad por la verdad misma, y que reconociendo la naturaleza humana en la plenitud de sus potencias ni la menoscaba, 
ni mutila la ciencia? Católico eș el pais; lo único que organizado está en él es el clero; el Colegio del Rosario quedó fundado por el Arzobispo Fray Cristóbal.de Torres para la enseñanza de la filosofía según la mente de Santo Tomás; y nuestra sociedad padece hambre y sed de justicia y tolerancia, que son la característica de la filosofía tomista. Más son los que hablan de Santo Tomás que los que lo han leído. Que lo lean para que lo amen y lo sigan.

He estudiado muchas de sus obras repetidas veces, y lo sigo con completa certidumbre. A Dios gracias soy católico apostólico romano por propio y espontáneo movimiento de mi conciencia. Mis convicciones son absolutamente desinteresadas, como también mis trabajos en la filosofía. Con serenidad y sin más deseo qua hallar la verdad y buscando la ciencia por la ciencia, he penetrado en el examen de los más grandes y seductores filósofos enemigos del catolicismo. He hallado en ellos verdades que, por serlo, caen en el campo de la filosofía tomista. Las he recogido, indicando sus lugares, para, como decía Santo Tomás y antes que él San Jerónimo, « reivindicar esas verdades de manos de injustos poseedores.» En esos ojeos icómo se huelga el alma al hallar un tomismo auténtico aunque entrevelado en los galanos filósofos a lo Fouillée y Ribot! Cuidadosamente he registrado las aserciones fundamentales contrarias a nuestro sistema, sustancialmente las he expuesto, con su fuente, y combatido con la mesura y decoro de que nuestro maestro Santo Tomás nos da el ejemplo. Por esto abundan las citaciones en el presente opúsculo, las cuales son, además, documentos comprobantes e índices con que los jóvenes pueden explanar sus estudios si felizmente lo desearen.

Para este trabajo todos ins dias me han sido de entresemana. Cuantos momentos he podido hurtar a mis deberes profesionales, he vacado a esta labor. Nadie me ha aliviado mi tarea. Cuanto en ella se contiene ha sido fruto de mi espíritu; de todo ello soy el único responsable. La revisión eclesiástica se limitó a su oficio. La médica la hizo benévola y pacientemente el doctor José María Montoya, cuyo honrosisimo testimonio publico en seguida.

El estudio de la Antropología es muy extenso; no es suficiente todo el curso anual a tan vasta materia. Para Protágoras "el hombre es la medida de todas las cosas," lo que en cierto sentido, en el que otros le daban llamando al hombre Micros cosmos, tiene mucho de verdad. Un texto sobre esa ciencia apenas alcanza a rozar, sin detallarlos, algunos de los numerosísimos puntos culminantes de tan complicada disciplina; otros o quedan idos de vista, u olvidados. Tócale al profesor colmar los vacios; bien preparado, esclarecerá el libro y podrá ampliarlo y mejorarlo y corregirlo por sus lecturas orales.

Sin duda estas materias filosóficas son difíciles de suyo, y nunca lo difícil dejará de serlo, especialmente para los jóvenes: Oficio, no de libros, sino de maestros, es allanarlas. Los libros de filosofía que se entienden a la primera lectura no contienen ciencia sino aquella vana palabrería que es la "engañosa fácilidad" de que habló el señor Rufino José Cuervo en su Advertencia a las notas que puso a la Gramática del señor Bello. Cuando uno de aquellos libros cae en manos de un principiante, y éste quiere darse cuenta de lo que está aprendiendo, su estudio encalla. Aquí el símil de Cornoldi de los dos crepúsculos: el de la mañana que empieza en la obscuridad y termina en plena luz, y el de la tarde, cuyo comienzo es luz y remata en tinieblas. Por cuya razón he huido, en mis opúsculos, del sistema de compendio, y más aún del extracto de obras ajenas.

Julio de 1917. 